\title{
Is pollen size a robust proxy for moisture availability?
}

2

3

Authors: Phillip E. Jardine ${ }^{\mathrm{a}^{*}}$ and Barry H. Lomax ${ }^{\mathrm{b}}$

4

5 a Institute of Earth and Environmental Science, University of Potsdam, 14476 Potsdam-Golm, 6 Germany.

7

$8{ }^{\mathrm{b}}$ The School of Biosciences, The University of Nottingham, Sutton Bonington Campus,

9 Leicestershire, LE12 5RD, UK.

10

$11 *$ Corresponding author

12 E-mail address: jardine@uni-muenster.de (P.E. Jardine)

13 Present address: Institute of Geology and Palaeontology, University of Münster, 48149

14 Münster, Germany.

15 


\section{Abstract}

17 The development of well-constrained palaeo-proxies that enable the reconstruction of past

18 climate change is becoming an ever more important field of scientific enquiry within the

19 palaeobotanical community, with the potential to deliver broader impacts linked to

20 understanding of future anthropogenic climate change. One of the major uncertainties in

21 predicting climate change is how the hydrological cycle will respond to future warming.

22 Griener and Warny (2015, Review of Palaeobotany and Palynology 221, 138-143) suggested

23 that pollen size might be a useful proxy for tracking moisture availability, as pollen size

24 appears to be negatively correlated with moisture. Given the long fossil record of pollen and

25 spores such a proxy would have broad scope and the potential to deliver much needed

26 information. Here we set out to fully evaluate and test the robustness of this proxy. We focus

27 on a number of a key issues: controls on pollen size, data analysis, and finally proxy

28 validation. Using this approach we find that there is little theoretical or empirical support for

29 the original relationship proposed by Griener and Warny. Consequently it is currently

30 premature to use pollen size as a moisture availability proxy in the fossil record. However,

31 we recognise that the technique may have potential and conclude by offering a series of

32 recommendations that would rigorously assess and test for a relationship between pollen size

33 and moisture availability.

35 Keywords

36 Pollen size, moisture availability, Nothofagus, phylogeny, palaeoclimate proxy 


\section{Introduction}

In the absence of direct measurements of climate in Earth's past, palaeoclimate

proxies have become essential for reconstructing climatic trends and ground-truthing climate models (Masson-Delmotte et al., 2013). However before these proxies can be deployed they need to be fully tested to assess both accuracy and the precession that underlie their predictive elements (Lomax and Fraser, 2015; Lomax et al., 2012). While fossil pollen and spores have traditionally been used in a passive manner (Jardine et al., 2016) to infer past climates based on the climatic tolerances of their nearest living extant relatives (e.g. Mosbrugger and Utescher, 1997; Utescher et al., 2014), there have also been attempts to use palynological morphological (Griener and Warny, 2015; Kürschner et al., 2013) and chemical data (Fraser et al., 2014; Fraser et al., 2011; Jardine et al., 2017; Jardine et al., 2016; Lomax and Fraser, 2015; Lomax et al., 2008; Rozema et al., 2009; Rozema et al., 2001a; Rozema et al., 2001b; Watson et al., 2007) to reconstruct climatic parameters more directly.

Griener and Warny (2015), hereafter G\&W15, introduced a proxy for moisture availability based on the size of pollen grains. This proxy is centered on the idea that larger pollen grains will be relatively more resistant to desiccation stress, because of a decreased surface area to volume ratio (Ejsmond et al., 2011; Griener and Warny, 2015). There should therefore be a negative correlation between moisture availability and pollen size at certain taxonomic levels (i.e. within species, genera or families). Moisture availability is a key climatic parameter (Wilf et al., 1998) and an important control on plant distributions (Engelbrecht et al., 2007; Gentry, 1988). A new, robust proxy for moisture availability would therefore be a particularly valuable tool for the scientific community. G\&W15 demonstrated

61 this proxy by relating the size of modern Nothofagus pollen grains to mean annual

62 precipitation (MAP), and then reconstructing size trends in Antarctic Nothofagidites 
lachlaniae-complex pollen grains from the Eocene to the Miocene. Partial validation of the

64

65

66

67

68

69

70

fossil pollen size data was carried out via a descriptive (i.e. non-statistical) comparison to the intrinsic water use efficiency ( $W U E_{i}$ ) of Eocene Nothofagus, derived from the carbon isotope discrimination ( $\Delta$ ) of Nothofagidites sporopollenin (Griener et al., 2013).

67

8 Here, we focus on a number of key issues that we have identified in the theoretical basis and validation of the moisture availability proxy of G\&W15. Specifically, we focus on three aspects: first, known controls on pollen size; second, the data analysis techniques employed by G\&W15 for validating their modern pollen size data, including a lack of accounting for phylogenetic autocorrelation; and third, the lack of supporting evidence for the palaeo-moisture availability reconstruction developed by G\&W15 in coeval fossil data.

Finally, we suggest some ways in which this proxy may be more fully developed and validated.

\section{Controls on pollen size}

\subsection{Genome size}

There is extensive literature showing that pollen size in extant plants is related to genome size and that this relationship scales with the level of ploidy (Bennett, 1972; De Storme et al., 2013). For example Bennett (1972) showed that there is a highly significant positive relationship between pollen volume and genome size in the grasses $(y=2.1+$ $\left.0.643^{*} \mathrm{x}, r^{2}=0.91, p<0.001, n=15\right)$. Although these data are not corrected for the effects of phylogeny (see section 3, below) it does highlight that factors other than moisture availability have the capacity to drive changes in pollen size and that these factors can explain a greater proportion of the variance. A full investigation of the relationship between pollen diameter and genome size indicates that relationship appears to hold within disparate plant groups 
especially when looking at ploidy but does not scale across broad groups when phylogeny is accounted for (Knight et al., 2010). These findings suggest that there is a strong phylogenetic signal (see section 3) that links pollen size to genome size and that is independent of environment.

There is some evidence for polyploidy being a selective advantage in dryer environments. The larger cells of polyploids can lead to higher xylem hydraulic conductance, for example (Thompson et al., 2015), as well as differences in stomatal apparatus (Manzaneda et al., 2012). Manzaneda et al. (2012) found that aridity is a strong predictor of ploidy level in the temperate grass Brachypodium distachyon, with tetraploid individuals having higher water use efficiency and increased tolerance to drought relative to diploid individuals. Further support for polyploidy conferring a selective advantage with regard to water stress comes from Garbutt and Bazzaz (1983), Watanabe (1986) and Li et al. (1996), all of whom demonstrated that polyploid plants are more tolerant of water stress than diploids. However, there is also evidence for polyploid plants being less well adapted to drought conditions (Baldwin, 1941). Similar dichotomous results are also found when comparing polyploid plants to diploids when looking for trends that confer cold tolerance and shade tolerance (see Maherali et al., 2009 for details). Taken together these findings suggest that while there is some tentative support for a general relationship between pollen size and moisture availability (Ejsmond et al., 2011; Griener and Warny, 2015), it is highly likely that this response would be mediated through genome size, rather than being a direct cause and effect relationship. Consequently, any other factors influencing the relationship between ploidy/genome size and habitat preference would bias the G\&W15 moisture availability proxy, limiting the inferences that could be made from it. 
115 pollen size (Christensen, 1946; Faegri and Iversen, 1975; Moore et al., 1991; Reitsma, 1969),

116 although this was not directly discussed by G\&W15, either in relation to their own samples

117 or as implications for future moisture availability reconstructions. This is particularly

118 important because G\&W15 treated their modern and fossil samples differently, with no

119 processing for the modern samples and a standard processing protocol of $\mathrm{HF}$ and $\mathrm{HCl}$ for the

120 fossil samples. HF has been shown to decrease the size of pollen grains (Faegri and Iversen,

121 1975; Moore et al., 1991; Schüler and Behling, 2011), meaning that the size changes

122 demonstrated by G\&W15 may not be directly comparable across datasets. Since no pollen

123 size-MAP calibration or quantitative precipitation estimates were attempted by G\&W15 this

124 in itself does not compromise their results, but it will need to be considered if this proxy is

125 developed further as a quantitative technique. Other processing methods not carried out by

$126 \mathrm{G} \& \mathrm{~W} 15$, such as treatment with $\mathrm{KOH}$ and acetolysis, have been reported to cause size

127 changes in palynomorphs (Christensen, 1946; Faegri and Iversen, 1975; Moore et al., 1991;

128 Reitsma, 1969), so as with HF care will need to be taken when analysing grain size trends

129 across sample sets that have undergone different processing protocols.

The choice of storage and mounting media is also known to have an impact on pollen

132 size (Andersen, 1960; Christensen, 1946; Cushing, 1961; Faegri and Iversen, 1975; Moore et

133 al., 1991; Reitsma, 1969; Sluyter, 1997). G\&W15 mounted their modern and fossil samples

134 in glycerine jelly, which can cause swelling of pollen grains, either through absorption of water from the atmosphere (Christensen, 1946; Moore et al., 1991) or softening of the exine

136 and subsequent deformation caused by pressure from the microscope coverslip (Cushing,

137 1961). G\&W15 did not state how long their samples were stored in glycerine jelly prior to 
analysis, so it is not possible to say how much of an impact it may have had on their reported measurements. Clearly any pollen size analyses that make use of samples that have been

140 stored in glycerine jelly will need to take possible size changes into account, especially if

141 different batches of samples were processed at different times. An alternative storage and

142 mounting medium such as silicone oil (Andersen, 1960; Sluyter, 1997) may be a better option

143 for pollen size measurements, or using coverslip supports (e.g. sand grains or splints from

144 other coverslips) to limit the downward pressure on the pollen grains (Cushing, 1961).

146 Finally, taphonomic processes will impact upon the size and shape of fossil

147 palynomorphs. Damage to pollen grains and spores through folding, pinching or breaking is a 148 common occurrence in fossil palynological samples (Havinga, 1967; Mander et al, 2012;

149 Tweddle and Edwards, 2010; Twiddle and Bunting, 2010), and makes consistent

150 measurements challenging, especially across changes in taphonomic regimes or in

151 comparison to modern specimens. Careful quality control will therefore be needed when

152 selecting specimens for measurement, which may limit the broader utility of the proxy unless

153 the target taxon is abundant and well-preserved through the time period of interest. Taken

154 together, these various factors show that care needs to be taken when selecting and

155 processing samples for pollen size analysis, and that all processing protocols need to be fully

156 reported in the literature. While these specific issues may not have compromised the analysis

157 in G\&W15, they will need to be carefully considered and taken into account in any further

158 research on pollen size-based proxies, whether these relate to moisture availability or genome 159 size in the fossil record.

160

161 3. Analysis of data 
Nothofagus pollen diameters taken from 19 herbarium specimens representing 12 species (not

16413 , as stated in G\&W15), with between 1 and 30 grains measured per specimen. G\&W15

165 tested the relationship between pollen size and mean annual precipitation using ordinary least

166 squares (OLS) linear regression, fitting a linear model though the mean values for each

167 sample. OLS regressions were carried out for the whole dataset together (Fig. 1 in G\&W15)

168 and separately for the subgenera Brassospora, Fuscospora and Nothofagus (Fig. S1 in

169 G\&W15). The subgenus Lophozonia is only represented by one measurement in the G\&W15

170 dataset, from the species N. obliqua, and so could not be modelled separately.

One of the underlying assumptions of OLS regression is that the values in the response variable are independent and identically distributed (i.i.d.) (Rohlf, 2006; Zuur et al., 2009). Data from a range of taxa are never truly independent, because the taxa will be in some way descended from a common ancestor, with more closely related species being more

176 similar than distantly related species (Garland and Ives, 2000). This phylogenetic signal in

177 the response variable violates the assumption of independence (Garland and Ives, 2000;

178 Martins and Hansen, 1997; Rohlf, 2006), inflating the Type 1 error rate (i.e. incorrectly rejecting a true null hypothesis, and finding a statistically significant result where none is present) (Rohlf, 2006). biological trait data (Cooper et al., 2016). One of the most commonly used is phylogenetic independent contrasts (PIC), which calculates differences (contrasts) between the character/trait values of pairs of sister taxa across the tips and nodes of a phylogeny

186 (Felsenstein, 1985; Garland et al., 1992; Garland and Ives, 2000). PIC implicitly assumes a 
187 Brownian motion model of trait evolution, i.e. an evolutionary random walk through trait space (Cooper et al., 2016; Garland and Ives, 2000). The calculated contrasts are phylogenetically independent and can be used in standard statistical analyses such as correlations, allowing for the role of phylogeny in driving the relationship to be assessed. For example from a palaeobotanical perspective PIC has been used to explore if carbon isotope

192 fractionation is driven by phylogeny (Lomax et al., 2012) and to determine that within angiosperms the relationship between genome size and guard cell length is independent of phylogeny (Beaulieu et al., 2008; Lomax et al., 2014), enabling broad scale reconstruction of the genome size of fossil plants (Lomax et al., 2014).

More recently, phylogenetic generalised least squares (P-GLS) regression has been developed, which allows for phylogenetic relatedness to be directly modelled as a correlation structure within the linear regression framework (Blomberg et al., 2012; Garland and Ives, 2000; Grafen, 1989; Martins and Hansen, 1997). P-GLS regression has the advantages that (i) it is more flexible than PIC, allowing for different underlying models of trait evolution (Rohlf, 2006), (ii) the variables can be modeled directly, rather than as contrasts (Garland and Ives, 2000), and (iii) it can be readily extended to more complex mixed effects models (Blomberg et al., 2012). However when a Brownian motion model of trait evolution is assumed in P-GLS regression the two techniques give identical results (Blomberg et al., 2012; Garland and Ives, 2000; Rohlf, 2006).

Here, we re-analyse the G\&W15 dataset using P-GLS. G\&W15 made their dataset

209 (specimen pollen size mean and standard deviation, and associated MAP) available in Table

210 S1 of their paper. We use the Nothofagus molecular phylogeny of Sauquet et al. (2012),

211 downloaded from TreeBASE (www.treebase.org) on 18/01/2017, to represent the 
212 phylogenetic relatedness among taxa. The phylogeny comprises 27 Nothofagus species (Fig

213 1), as well as 21 outgroup species from the core Fagales, and so was first trimmed down to

214 the taxa represented in the G\&W15 dataset. Nothofagus rubra and Nothofagus starkenborghii

215 are not present in the molecular phylogeny, and so were removed from the G\&W15 dataset.

216 The pollen size and MAP means for the remaining 10 taxa were then calculated for use in the

217 P-GLS regression. We used a simple Brownian motion model of trait evolution across the

218 trimmed Nothofagus phylogeny as a correlation structure in the P-GLS regression. Data

219 analysis was carried out in R v. 3.3.1 (Team, 2016) using the packages ape v. 4.1 (Paradis et

220 al., 2004), phytools v. 0.5-64 (Revell, 2012), nlme v. 3.1-131 (Pinheiro et al., 2017) and

221 astrochron v. 0.6.5 (Meyers, 2014).

222

223

Mapping pollen size directly onto the molecular phylogeny using ancestral character

estimation (Revell, 2013) shows a degree of phylogenetic structuring (i.e. similar values in

the sister taxa $N$. carrii and $N$. grandis, and $N$. dombeyi and $N$. betuloides), confirming the importance of correcting for phylogenetic non-independence in the regression model (Fig 2a; see also Fernández et al., 2016). Regressing pollen size onto MAP (pollen size is the response or dependent variable, MAP is the explanatory or independent variable) using P-GLS regression gives the model $\mathrm{y}=35.2-0.003^{*} \mathrm{x}, p=0.003, n=10$, whereas an OLS regression of the same version of the dataset gives the model $\mathrm{y}=38.4-0.005^{*} \mathrm{x}, p=0.0006, n=10$ (Fig 2b). While both model fits are statistically significant, the $p$ value is an order of magnitude lower in the P-GLS model, and the slope is also shallower. The different slopes between the two models shows the importance of including phylogeny for any regression models being used for calibration and quantitative moisture availability reconstructions. 
There is also the more general point that the G\&W15 dataset itself is quite small, with

limited replication of individual plants within each species. Seven of the species in the dataset are represented by just one herbarium specimen, three by two specimens, and two by three specimens. This not only makes it challenging to look at within-species variation, to

240 investigate whether populations at different MAP levels exhibit differences in pollen size, but 241 also makes it impossible to assess whether non-significant relationships at the subgenus level are due to a genuine lack of a response to moisture availability or insufficient data. G\&W15 carried out regressions for the three subgenera with more than one species represented, and only found a significant relationship for one of them, Brassospora (Fig. 3, note that the subgenus Nothofagus was reported as significant but had a $p$ value of $<0.17$ in G\&W15). The significant relationship for Brassospora is largely driven by one outlier, the species $N$. discoidea, which with a mean grain size of $32.1 \mu \mathrm{m}$ is considerably larger than the other Brassospora species sampled (Figs. 3 and 2a). Removing the $N$. discoidea data point from the dataset and re-running the regression reduces the slope of the fitted model from -0.006 to 0.003 , the $r^{2}$ from 0.73 to 0.28 , and the $p$ value from 0.003 to 0.18 (i.e. the relationship is no longer statistically significant without this one species). There is therefore limited evidence for a consistent, statistically robust relationship between pollen size and MAP below the level of genus. While this is very possibly down to the small sample sizes involved, this in itself suggests that the dataset used by G\&W15 is too limited to robustly validate this proxy, and that further replication across taxonomic ranks is needed if it is to be confidently deployed as a palaeoclimate proxy.

\section{Lack of evidence in fossil data}

Past moisture availability reconstructions based on fossil pollen size should show good agreement with other moisture availability or precipitation proxies (assuming these 
themselves are broadly reliable). G\&W15 measured Nothofagidites lachlaniae-complex

pollen size from the Eocene to the Miocene of the Antarctic Peninsula (data available in

Table S2 of G\&W15), and interpreted changes in the context of moisture availability. Griener

et al. (2013) generated a moisture availability proxy record for the late Eocene portion of the same cores, based on Nothofagidites pollen $\delta^{13} \mathrm{C}$ discrimination. The $\Delta^{13} \mathrm{C}$ record shows an overall decrease through time, suggesting a decrease in moisture availability, and thus we would expect this to be reflected in a trend towards larger pollen sizes (i.e. the two records should show a negative correlation).

The decrease in moisture availability suggested by the $\Delta{ }^{13} \mathrm{C}$ dataset is less clear in the pollen size dataset, however, especially given the large errors on the pollen size means (Fig. 4a). Interpolating the $\Delta^{13} \mathrm{C}$ data to the same depth levels as the size data, and regressing size onto $\Delta^{13} \mathrm{C}$ with OSL regression gives the model $\mathrm{y}=33.40-0.48^{*} \mathrm{x}, r^{2}=0.08, p=0.37, n=$ 12 (Fig. 4b). Therefore the regression reveals the expected negative correlation, but the relationship is not statistically significant and the $\Delta^{13} \mathrm{C}$ data only explains a small proportion of the variance in the pollen size data. The negative correlation between pollen size and $\Delta^{13} \mathrm{C}$ is also largely driven by one extreme value (Fig. 4b). Given that the size and discrimination data have been developed on the same plant group from the same sedimentary record this result offers no support for a link between moisture availability and pollen size. This proxy therefore cannot be successfully validated in the fossil record, although we acknowledge that other factors that drive stomatal closure (such as elevated $\mathrm{CO}_{2}$ ) which control discrimination could also influence $\Delta^{13} \mathrm{C}$. However experimental work has shown that water availability does act as a primary control on $\Delta^{13} \mathrm{C}$ even over a range of $\mathrm{CO}_{2}$ concentrations relevant to the geological record (Lomax et al., 2012). 


\section{Suggestions for further proxy development}

For the reasons outlined above, we feel that it is currently premature to use pollen size as a moisture availability proxy in the fossil record. In order to fully test and validate this as a robust proxy, we suggest that the following measures are needed:

291 1. A better understanding of the relationship(s) between genome size, abiotic factors including moisture availability and pollen size.

2. Considerably more modern pollen size data, with greater replication across taxonomic

294 ranks, to robustly quantify the relationship between pollen size and moisture availability.

295 Analysis of these data will require a proper accounting for phylogenetic dependency, and also 296 any spatial autocorrelation between sampling localities (Zuur et al., 2009).

297 3. Data from controlled growth experiments, with pollen harvested from plants grown under a range of environmental conditions, to better understand the external controls on pollen size within and among species.

300 4. Further palaeo-palynological datasets where there are existing precipitation indicators, to

301 allow for validation in the fossil record. Quaternary pollen records may be best suited to this, 302 because of better-constrained environmental conditions compared to the deep time fossil 303 record.

\section{Acknowledgements}

306 We would like to thank Surangi Punyasena and one anonymous reviewer, whose comments 307 greatly improved this paper. We would also like to thank Kathryn Griener and Sophie Warny 308 for making their dataset freely available alongside their paper, which allowed for this 309 reanalysis to be carried out. B.H.L.'s research on palaeogenome size was funded via NERC 
310 New Investigators grant NE/J004855/1. P.E.J. was funded by ERC grant 649081 (MAGIC)

311 and NERC standard grant NE/K005294/1.

312

\section{References}

314 Andersen, S.T., 1960. Silicone oil as a mounting medium for pollen grains. Danmarks

315 Geologiske Undersøgelse (Series) IV 1, 1-24.

316

317 Baldwin, T.J., 1941. Galax: the genus and its chromosomes. Journal of Heredity 32, 249-254.

319 Beaulieu, J.M., Leitch, I.J., Patel, S., Pendharkar, A., Knight, C.A., 2008. Genome size is a 320 strong predictor of cell size and stomatal density in angiosperms. New Phytologist 179, 975321 986.

Bennett, M.D., 1972. Nuclear DNA Content and Minimum Generation Time in Herbaceous

Plants. Proceedings of the Royal Society of London B: Biological Sciences 181, 109-135.

326 Blomberg, S.P., Lefevre, J.G., Wells, J.A., Waterhouse, M., 2012. Independent contrasts and PGLS regression estimators are equivalent. Systematic Biology 61, 382-391.

329 Christensen, B.B., 1946. Measurement as a means of identifying fossil pollen. Danmarks

330 Geologiske Undersøgelse (Series) IV 3(2), 1-22.

331

332 Cooper, N., Thomas, G.H., FitzJohn, R.G., 2016. Shedding light on the 'dark side' of

333 phylogenetic comparative methods. Methods in Ecology and Evolution 7, 693-699. 
335 Cushing, E.J., 1961. Size increase in pollen grains mounted in thin slides. Pollen et Spores $3363(2), 265-274$.

337

338 De Storme, N., Zamariola, L., Mau, M., Sharbel, T.F., Geelen, D., 2013. Volume-based

339 pollen size analysis: an advanced method to assess somatic and gametophytic ploidy in

340 flowering plants. Plant Reproduction 26, 65-81.

341

342 Ejsmond, M.J., Wrońska-Pilarek, D., Ejsmond, A., Dragosz-Kluska, D., Karpińska-Kołaczek,

343 M., Kołaczek, P., Kozłowski, J., 2011. Does climate affect pollen morphology? Optimal size

344 and shape of pollen grains under various desiccation intensity. Ecosphere 2, 1-15.

346 Engelbrecht, B.M., Comita, L.S., Condit, R., Kursar, T.A., Tyree, M.T., Turner, B.L.,

347 Hubbell, S.P., 2007. Drought sensitivity shapes species distribution patterns in tropical

348 forests. Nature 447, 80-82.

350 Faegri, K., Iversen, J., 1975. Textbook of pollen analysis, $3^{\text {rd }}$ edition. Munksgaard, 351 Copenhagen.

353 Felsenstein, J., 1985. Phylogenies and the comparative method. American Naturalist 125, 135415.

356 Fernández, D.A., Santamarina, P.E., Tellería, M.C., Palazzesi, L., Barreda, V.D., 2016.

357 Pollen morphology of Nothofagus (Nothofagaceae, Fagales) and its phylogenetic 358 significance. Acta Palaeobotanica 56, 223-245. 
360 Fraser, W.T., Lomax, B.H., Jardine, P.E., Gosling, W.D., Sephton, M.A., 2014. Pollen and spores as a passive monitor of ultraviolet radiation. Frontiers in Ecology and Evolution 2:12 . http://dx.doi.org/10.3389/fevo.2014.00012

364 Fraser, W.T., Sephton, M.A., Watson, J.S., Self, S., Lomax, B.H., James, D.I., Wellman, 365 C.H., Callaghan, T.V., Beerling, D.J., 2011. UV-B absorbing pigments in spores: biochemical responses to shade in a high-latitude birch forest and implications for sporopollenin-based proxies of past environmental change. Polar Research 30, 8312.

Garbutt, K., Bazzaz, F.A., 1983. Leaf demography, flower production and biomass of diploid and tetraploid populations of Phlox drummondii Hook. on a soil moisture gradient. New Phytologist 93, 129-141.

Garland, T.J., Harvey, P.H., Ives, A.R., 1992. Procedures for the analysis of comparative data using phylogenetically independent contrasts. Systematic Biology 41, 18-32.

Garland, T.J., Ives, A.R., 2000. Using the Past to Predict the Present: Confidence Intervals for Regression Equations in Phylogenetic Comparative Methods. The American Naturalist 155, 346-364.

380 Gentry, A.H., 1988. Changes in plant community diversity and floristic composition on environmental and geographical gradients. Annals of the Missouri Botanical Garden 75, 134. 
384 Grafen, A., 1989. The phylogenetic regression. Philosophical Transactions of the Royal

385 Society of London B: Biological Sciences 326, 119-157.

386

387 Griener, K.W., Nelson, D.M., Warny, S., 2013. Declining moisture availability on the

388 Antarctic Peninsula during the Late Eocene. Palaeogeography, Palaeoclimatology,

389 Palaeoecology 383-384, 72-78.

390

391 Griener, K.W., Warny, S., 2015. Nothofagus pollen grain size as a proxy for long-term

392 climate change: An applied study on Eocene, Oligocene, and Miocene sediments from

393 Antarctica. Review of Palaeobotany and Palynology 221, 138-143.

394

395 Havinga, A.J., 1967. Palynology and pollen preservation. Review of Palaeobotany and 396 Palynology 2, 81-98.

397

398 Jardine, P.E., Abernethy, F.A.J., Lomax, B.H., Gosling, W.D., Fraser, W.T., 2017. Shedding

399 light on sporopollenin chemistry, with reference to UV reconstructions. Review of

400 Palaeobotany and Palynology 238, 1-6.

401

402 Jardine, P.E., Fraser, W.T., Lomax, B.H., Sephton, M.A., Shanahan, T.M., Miller, C.S.,

403 Gosling, W.D., 2016. Pollen and spores as biological recorders of past ultraviolet irradiance.

404 Scientific Reports 6, 1-8.

405

406 Knight, C.A., Clancy, R.B., Götzenberger, L., Dann, L., Beaulieu, J.M., 2010. On the

407 Relationship between Pollen Size and Genome Size. Journal of Botany 2010, 612017. 408 
409 Kürschner, W.M., Batenburg, S.J., Mander, L., 2013. Aberrant Classopollis pollen reveals

410 evidence for unreduced (2n) pollen in the conifer family Cheirolepidiaceae during the

411 Triassic-Jurassic transition. Proceedings of the Royal Society of London B: Biological

412 Sciences 280, 20131708.

413

414 Li, W.-L., Berlyn, G.P., Ashton, P.M.S., 1996. Polyploids and their structural and

415 physiological characteristics relative to water deficit in Betula papyrifera (Betulaceae).

416 American Journal of Botany 83, 15-20.

417

418 Lomax, B.H., Fraser, W.T., 2015. Palaeoproxies: Botanical monitors and recorders of

419 atmospheric change. Palaeontology 58, 759-768.

420

421

Lomax, B.H., Fraser, W.T., Sephton, M.A., Callaghan, T.V., Self, S., Harfoot, M., Pyle, J.A.,

Wellman, C.H., Beerling, D.J., 2008. Plant spore walls as a record of long-term changes in ultraviolet-B radiation. Nature Geoscience 1, 592-596.

424

425

Lomax, B.H., Hilton, J., Bateman, R.M., Upchurch, G.R., Lake, J.A., Leitch, I.J., Cromwell, 426

A., Knight, C.A., 2014. Reconstructing relative genome size of vascular plants through geological time. New Phytologist 201, 636-644.

428

429 Lomax, B.H., Knight, C.A., Lake, J.A., 2012. An experimental evaluation of the use of $\mathrm{C}_{3} \delta$

$430{ }^{13} \mathrm{C}$ plant tissue as a proxy for the paleoatmospheric $\delta{ }^{13} \mathrm{CO}_{2}$ signature of air. Geochemistry, 431 Geophysics, Geosystems 13, Q0AI03. 
Maherali, H., Walden, A.E., Husband, B.C., 2009. Genome duplication and the evolution of physiological responses to water stress. New Phytologist 184, 721-731.

435

Mander, L., Wesseln, C.J., McElwain, J.C., Punyasena, S.W., 2012. Tracking taphonomic regimes using chemical and mechanical damage of pollen and spores: an example from the Triassic-Jurassic mass extinction. PloS ONE, 7(11), e49153.

439

Manzaneda, A.J., Rey, P.J., Bastida, J.M., Weiss-Lehman, C., Raskin, E., Mitchell-Olds, T.,

2012. Environmental aridity is associated with cytotype segregation and polyploidy occurrence in Brachypodium distachyon (Poaceae). New Phytologist 193, 797-805.

Martins, E.P., Hansen, T.F., 1997. Phylogenies and the comparative method: a general approach to incorporating phylogenetic information into the analysis of interspecific data. The American Naturalist 149, 646-667.

447

Masson-Delmotte, V., Schulz, M., Abe-Ouchi, A., Beer, J., Ganopolski, A., González Rouco, 449 J.F., Jansen, E., Lambeck, K., Luterbacher, J., Naish, T., Osborn, T., Otto-Bliesner, B., 450 Quinn, T., Ramesh, R., Rojas, M., Shao, X., Timmermann, A., 2013. Information from Paleoclimate Archives, in: Stocker, T.F., Qin, D., Plattner, G.-K., Tignor, M., Allen, S.K., 452 Boschung, J., Nauels, A., Xia, Y., Bex, V., Midgley, P.M. (Eds.), Climate Change 2013: The 453 Physical Science Basis. Contribution of Working Group I to the Fifth Assessment Report of 454 the Intergovernmental Panel on Climate Change. Cambridge, United Kingdom and New 455 York, NY, USA.: Cambridge University Press, 383-464.

456 
Meyers, S.R., 2014. Astrochron: An R Package for Astrochronology. http://cran.r-

project.org/package=astrochron

459

460 Moore, P.D., Webb, J.A., Collinson, M.E., 1991. Pollen Analysis, $2^{\text {nd }}$ edition. Blackwell

461 Science Ltd, Oxford.

462

463

Mosbrugger, V., Utescher, T., 1997. The coexistence approach - a method for quantitative

464

reconstructions of Tertiary terrestrial palaeoclimate data using plant fossils. Palaeogeography,

Palaeoclimatology, Palaeoecology 134, 61-86.

466

467

Paradis, E., Claude, J., Strimmer, K., 2004. APE: analyses of phylogenetics and evolution in

468

R language. Bioinformatics 20, 289-290. http://cran.r-project.org/package=ape

469

470

Pinheiro, J., Bates, D., DebRoy, S., Sarkar, D., Team, R.C., 2017. nlme: Linear and

471

Nonlinear Mixed Effects Models, 3.1-128 ed. http://cran.r-project.org/package=nlme

472

473 R Core Team 2016. R: A language and environment for statistical computing. R Foundation

474 for Statistical Computing, Vienna, Austria. https://www.R-project.org/

475

476

Reitsma, T.J., 1969. Size modification of recent pollen grains under different treatments.

477 Review of Palaeobotany and Palynology 9(3), 175-202.

478

479 Revell, L.J., 2012. phytools: An R package for phylogenetic comparative biology (and other

480 things). Methods in Ecology and Evolution 3, 217-223. http://cran.r-

481 project.org/package=phytools 
483 Revell, L.J., 2013. Two new graphical methods for mapping trait evolution on phylogenies.

Methods in Ecology and Evolution 4, 754-759.

485

Rohlf, F.J., 2006. A comment on phylogenetic correction. Evolution 60, 1509-1515.

487

Rozema, J., Blokker, P., Mayoral Fuertes, M.A., Broekman, R., 2009. UV-B absorbing

compounds in present-day and fossil pollen, spores, cuticles, seed coats and wood: evaluation

of a proxy for solar UV radiation. Photochemical and Photobiological Sciences 8, 1233-1243.

Rozema, J., Broekman, R.A., Blokker, P., Meijkamp, B., de Bakker, N., van de Staaij, J., van

Beem, A., Ariese, F., Kars, S.M., 2001a. UV-B absorbance and UV-B absorbing compounds (para-coumaric acid) in pollen and sporopollenin: the perspective to track historic UV-B levels. Journal of Photochemistry and Photobiology B: Biology 62, 108-117.

496

497

Rozema, J., Noordjik, A.J., Broekman, R.A., van Beem, A., Meijkamp, B.M., de Bakker, N.V.J., van de Staaij, J.W.M., Stroetenga, M., Bohncke, S.J.P., Konert, M., Kars, S., Peat, H., Smith, R.I.L., Convey, P., 2001b. (Poly)phenolic compounds in pollen and spores of Antarctic plants as indicators of UV-B: A new proxy for the reconstruction of past solar UVB? Plant Ecology 154, 11-26.

502

503

Sauquet, H., Ho, S.Y., Gandolfo, M.A., Jordan, G.J., Wilf, P., Cantrill, D.J., Bayly, M.J.,

504 Bromham, L., Brown, G.K., Carpenter, R.J., Lee, D.M., Murphy, D.J., Sniderman, J.M., Udovicic, F., 2012. Testing the impact of calibration on molecular divergence times using a

506 fossil-rich group: the case of Nothofagus (Fagales). Systematic Biology 61, 289-313. 
508 Schüler, L., Behling, H., 2011. Poaceae pollen grain size as a tool to distinguish past

509 grasslands in South America: a new methodological approach. Vegetation History and

510 Archaeobotany 20, 83-96.

511

512 Sluyter, A., 1997. Analysis of maize (Zea mays subsp. mays) pollen: normalizing the effects

513 of microscope-slide mounting media on diameter determinations. Palynology 21, 35-39.

514

515 Thompson, K.A., Husband, B.C., Maherali, H., Bonser, S., 2015. No influence of water

516 limitation on the outcome of competition between diploid and tetraploid Chamerion

517 angustifolium (Onagraceae). Journal of Ecology 103, 733-741.

518

519 Tweddle, J.C., Edwards, K.J., 2010. Pollen preservation zones as an interpretive tool in

520 Holocene palynology. Review of Palaeobotany and Palynology 161, 59-76.

521

522 Twiddle, C.L., Bunting, M.J., 2010. Experimental investigations into the preservation of

523 pollen grains: A pilot study of four pollen types. Review of Palaeobotany and Palynology $524162,621-630$.

525

526 Utescher, T., Bruch, A.A., Erdei, B., François, I., Ivanov, D., Jacques, F.M.B., Kern, A.K., 527 Liu, Y.-S.C., Mosbrugger, V., Spicer, R.A., 2014. The Coexistence Approach - Theoretical 528 background and practical considerations of using plant fossils for climate quantification. 529 Palaeogeography, Palaeoclimatology, Palaeoecology 410, 58-73. 
531 Watanabe, K., 1986. The cytogeography of the genus Eupatorium (Compositae) - a review.

532 Plant Species Biology 1, 99-116.

533

534 Watson, J.S., Septhon, M.A., Sephton, S.V., Self, S., Fraser, W.T., Lomax, B.H., Gilmour, I.,

535 Wellman, C.H., Beerling, D.J., 2007. Rapid determination of spore chemistry using

536 thermochemolysis gas chromatography-mass spectrometry and micro-Fourier transform

537 infrared spectroscopy. Photochemistry and Photobiology 6, 689-694.

538

539 Wilf, P., Wing, S.L., Greenwood, D.R., Greenwood, C.L., 1998. Using fossil leaves as

540 paleoprecipitation indicators: An Eocene example. Geology 26, 203-206.

541

542 Zuur, A.F., Ieno, E.N., Walker, N.J., Saveliev, A.A., Smith, G.M., 2009. Mixed effects

543 models and extensions in ecology with R. Springer, New York.

544 
546 Fig. 1. Nothofagus phylogeny of Sauquet et al. (2012), with the taxa in the G\&W15 dataset in 547 bold type.

549 Fig. 2. A) Nothofagus phylogeny of Sauquet et al. (2012) limited to the taxa in the G\&W15 550 dataset, with pollen size mapped on using ancestral character estimation (Revell, 2013). B)

551 Pollen size plotted against mean annual precipitation, showing the mean values for each species. Dashed line = ordinary least squares $(\mathrm{OSL})$ model, solid line $=$ phylogenetic generalised least squares (P-GLS) model.

Fig. 3. Nothofagus pollen size from G\&W15 plotted against mean annual precipitation, showing the mean values for each specimen and OSL regression fits for each subgenus (solid lines are fitted models, dashed lines are 95\% confidence intervals). Individual regression models are: Brassospora, $\mathrm{y}=39.90-0.006^{*} \mathrm{x}, r^{2}=0.73, p=0.003, n=9 ;$ Fuscospora, $\mathrm{y}=$ $31.55-0.002 * \mathrm{x}, r^{2}=0.37, p=0.28, n=5 ;$ Nothofagus, $\mathrm{y}=35.47-0.005 * \mathrm{x}, r^{2}=0.89, p=$ $560 \quad 0.06, n=4$.

561

562 Fig. 4. A) Eocene Nothofagidites pollen size and $\Delta^{13} \mathrm{C}$ data for the SHALDRIL 3C core. Black points and line $=\Delta{ }^{13} \mathrm{C}$ data from Griener et al. (2013). Grey points with error bars $=$ pollen size data from G\&W15, points are sample means and error bars are 1 standard deviation. B) Eocene Nothofagidites pollen size regressed against Nothofagidites $\Delta^{13} \mathrm{C}$, with the $\Delta^{13} \mathrm{C}$ data interpolated to the same sampling depths as the pollen size data. Black solid line is the fitted regression model, dashed lines are $95 \%$ confidence intervals. 


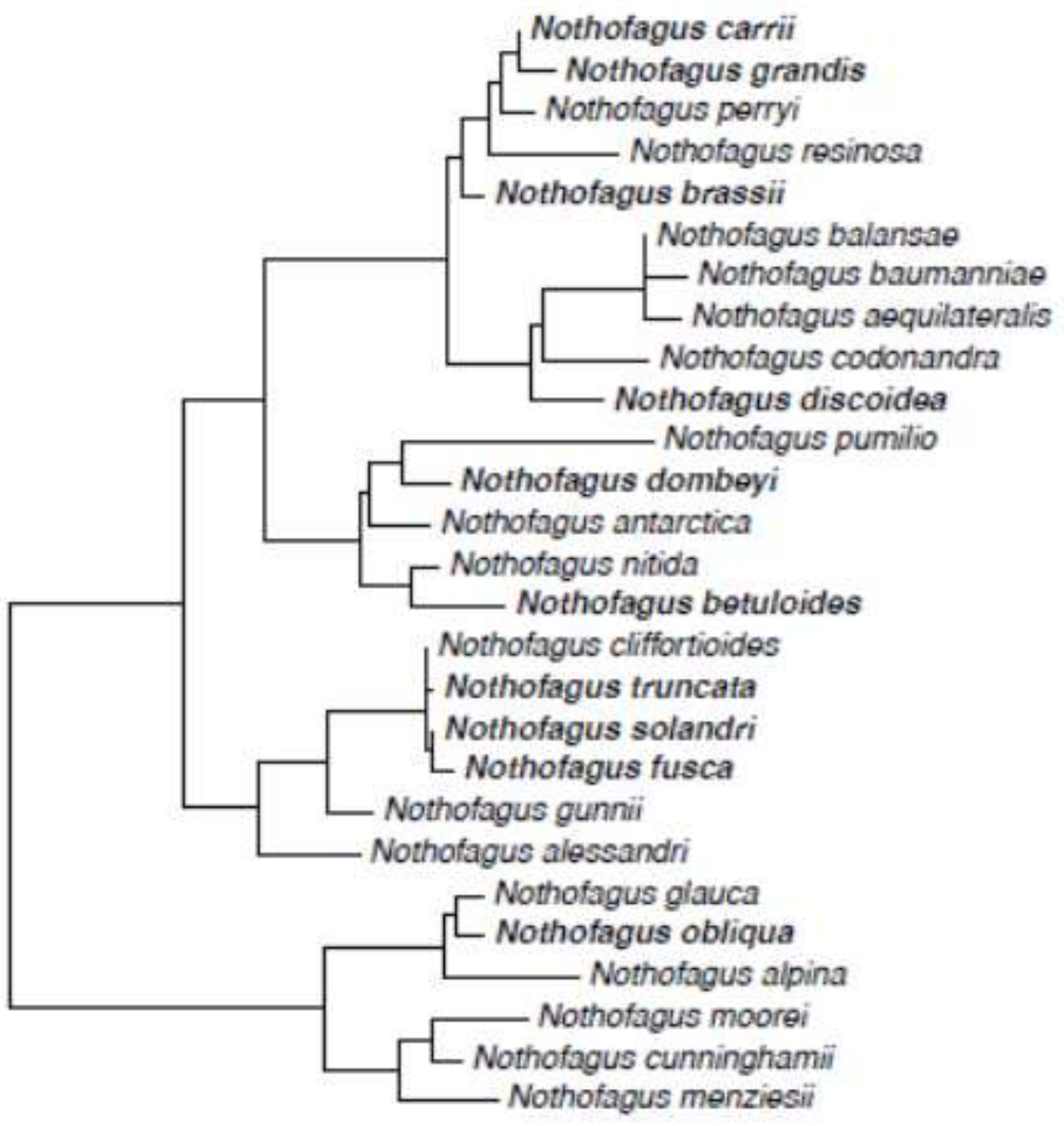

क
के
के
$\frac{8}{8}$
0

ख

है

5
8
8
0
5

Jardine and Lomax

Is pollen size a robust proxy for moisture availability?

571

Figure 1 

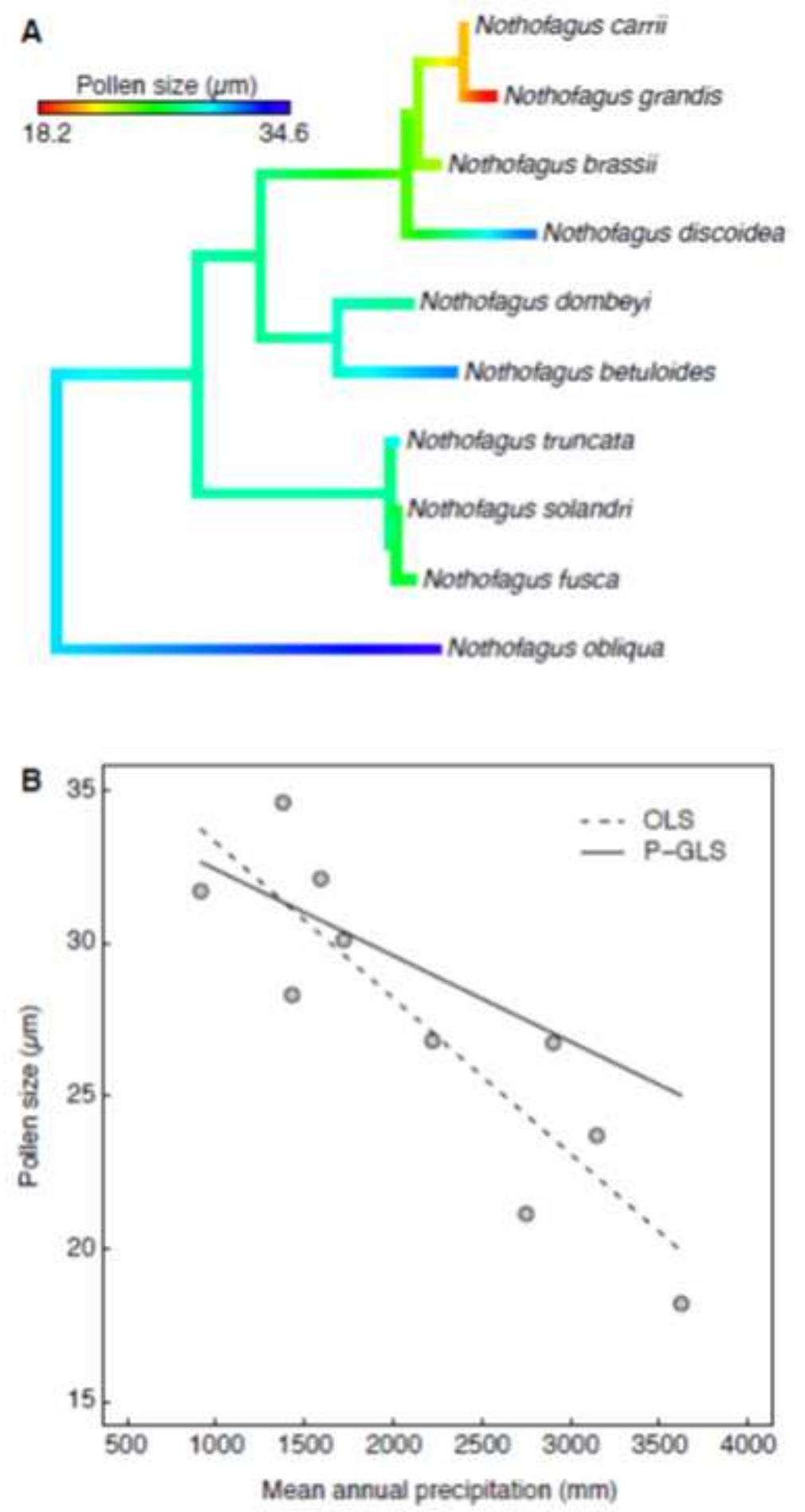

Jardine and Lomax Is pollen size a robust proxy for moisture availability? Figure 2 


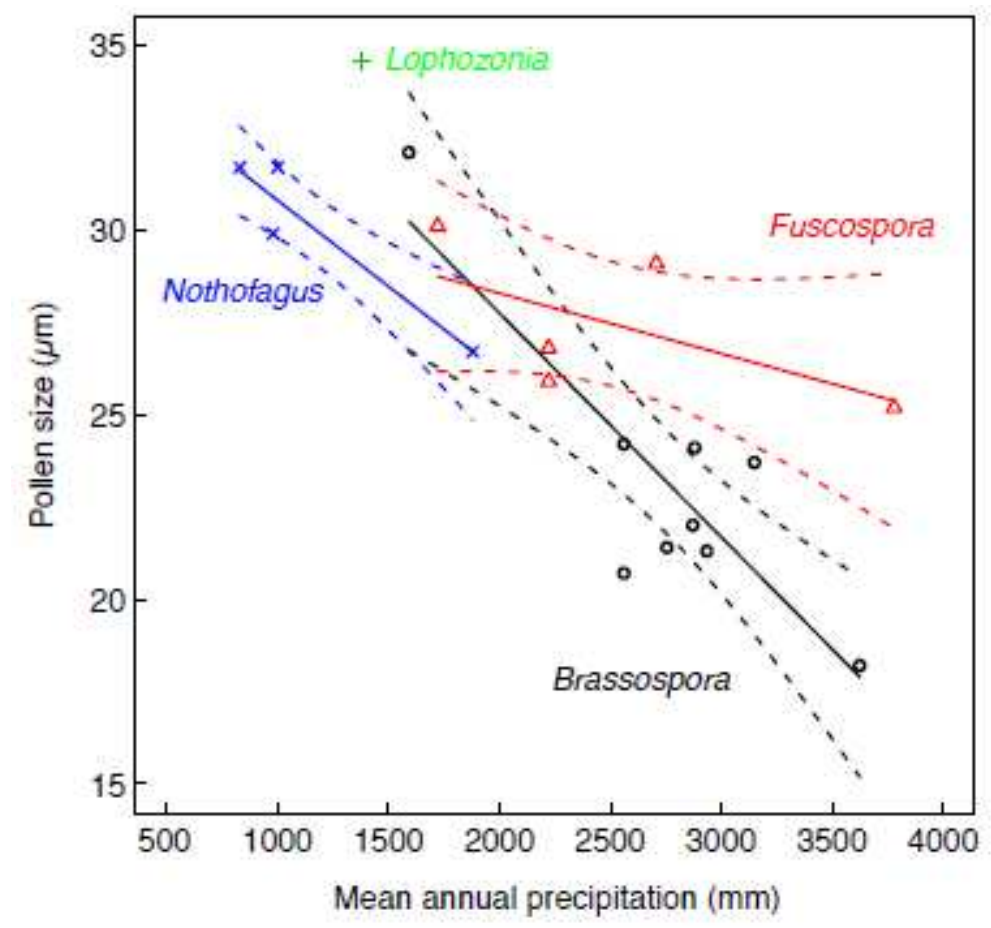

Jardine and Lomax

Is pollen size a robust proxy for moisture availability? 

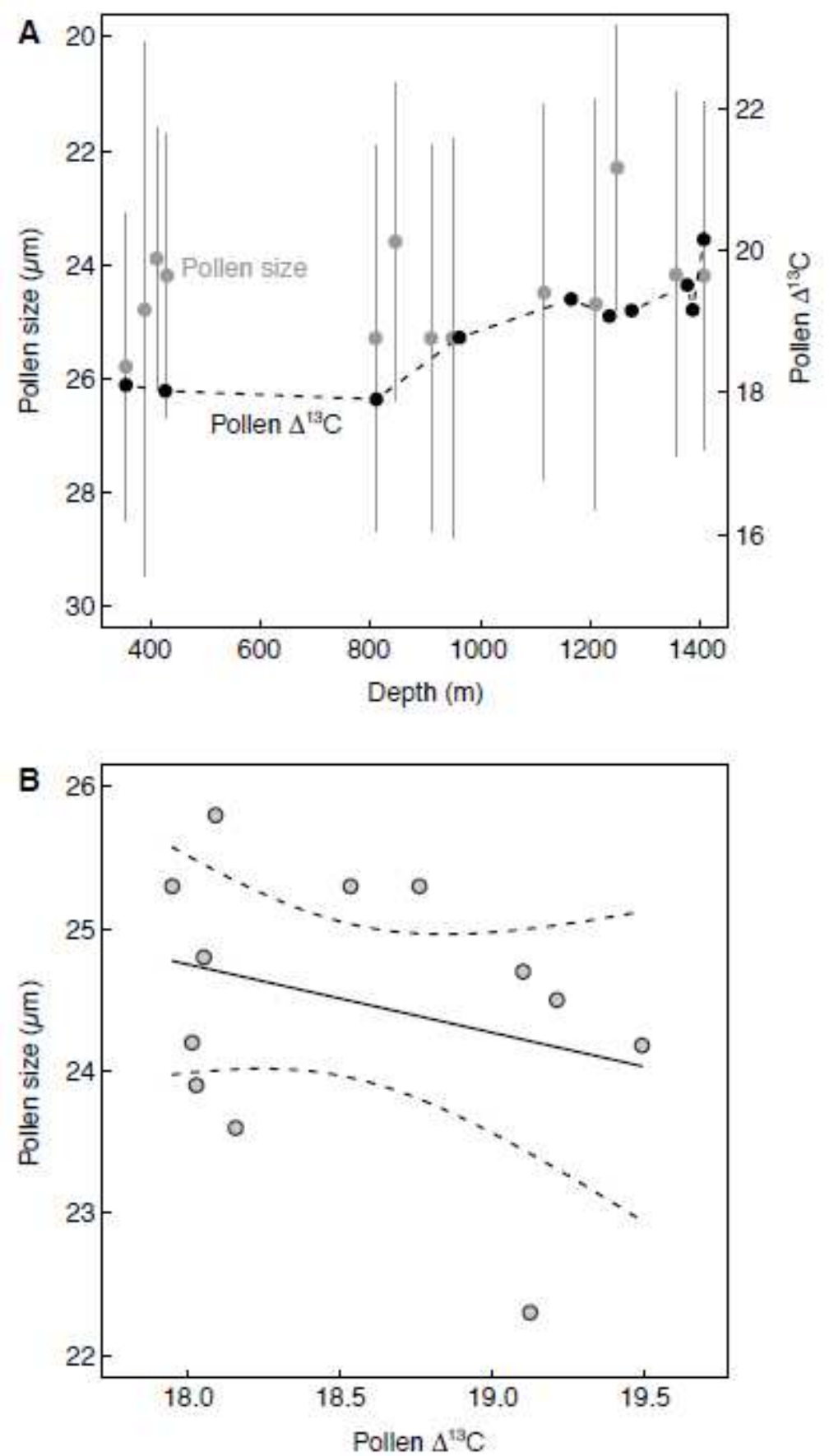

Jardine and Lomax

Is pollen size a robust proxy for moisture availability?

Figure 4 